\title{
A CONSTRUÇÃO DO CONHECIMENTO: UMA TEORIA ABELARDIANA
}

\section{Izabela Domingos Da Silva ${ }^{1}$ \\ Dr. Anderson D'Arc Ferreira}

\begin{abstract}
RESUMO
O presente trabalho visa apresentar, de forma sucinta, uma breve análise acerca do processo Intelectivo descrito por Pedro Abelardo em sua obra De Intellectibus. Trataremos das duas formas para as quais o processo intelectivo se volta, fazendo uma maior referência ao processo lógico, pois iremos considerar apenas as proposições com uma construção correta e que possuam correspondentes no mundo, ou ainda, das quais possa ser atestado um valor de verdade. Dentro das intelecções lógicas trataremos dos tipos de intelecção e do papel da linguagem nesse processo. No ponto de vista de Abelardo as palavras passam a ser tidas como voz dotada de significado, portanto, algo previamente estabelecido pelo homem e que, a partir de disso, faz com que ela "imprima" seu significado na alma. Por fim, buscaremos expor que a questão da intelecção não se atém apenas à teoria da linguagem, mas também a uma teoria do conhecimento. É a forma como Abelardo descreve a relação da nossa mente com o mundo.
\end{abstract}

Palavras-chave: Pedro Abelardo; Intelecção; Linguagem; Teoria do conhecimento.

\section{Introdução}

Um dos grandes debates que ocorreram na filosofia da Idade Média e, de certa forma, perdura até hoje foi o chamado problema dos universais. Neste contexto do século XII Pedro Abelardo teve seus primeiros contatos com a corrente Nominalista, ao estudar com Roscelino de Compiegne. Sabe-se que o nominalismo é a linha que, em resposta a querela dos universais, os classifica como meras emissões vocais - nominalens; que não estão na realidade. Segundo ele, o que podemos observar no mundo são apenas os particulares, pois os universais são incorpóreos e existem apenas na mente. "Fora desta realidade física, constituída pelo sopro da voz, os universais nada seriam, pois

1 Doutoranda do Curso de Filosofia da Universidade Federal da Paraíba, componente do Grupo de Estudo em Filosofia Patrística e Medieval UFPB/CNPq, coordenado pelo Professor Anderson D’Arc Ferreira. E-mail: Izabela.domingos@hotmail.com

2 Doutor em Filosofia. Professor da UFPB. E-mail: andersondarc@uai.com.br, 
na realidade só existem os indivíduos. A humanidade nada mais é do que um mero nome".

Após discordar de seu mestre Roscelino, Abelardo vai para Paris e passa a ter aulas com Guilherme de Champeuax. A posição adotada por Guilherme era realista, porém, desde cedo, eram rejeitadas por Abelardo. Ele acreditava que a vertente extrema do realismo causava problemas de cunho lógico:

É nesse ínterim que Pedro de Pallet passa a investigar as questões lógicas que envolvem o problema dos universais e a linguagem. Fica claro para nós que esse caminho o levou à investigação da formação do conhecimento. As principais obras de Pedro Abelardo consultadas para nossa pesquisa (a saber, Lógica Ingredientibus e Tractatus de Intellectibus), mostram que é preciso chegar ao entendimento do processo intelectivo antes de abordar a questão do conhecimento. Veremos que é através da noção de intelecto que sua teoria será construída. Não há uma delimitação em suas obras, porém temos a compreensão de que o processo intelectivo faz parte da possibilidade do conhecer. Tanto na Logica Ingredientibus quanto no Tractatus, desde o momento em que ele diferencia a opinião da intelecção, notaremos como o intelecto será parte fundamental do conhecer em ato.

\section{Desenvolvimento}

As intelecções dividem-se em dois grandes grupos, a saber, intelecçõeslógicas e gramáticas. Esta divisão é feita no Logica Ingredientibus, ao definir lógicos e gramáticos e retomada no Tractatus de Intellectibus direcionada exclusivamente às intelecções.

Abelardo denomina no Lógica para Principiantes a intelecção como: "[...] uma certa ação da alma, pela qual é chamada de inteligente, e a forma para qual se dirige é uma certa coisa imaginária e fictícia, que o espírito elabora para si quando e como quer [...]" (ABELARDO, 1994, p. 62-63). Nosso autor irá mostrar que a intelecção é uma afecção da alma diferente das outras e a maneira como ela se relaciona com o universal e o conhecimento. Façamos uma análise da definição dada por ele:

1. Uma certa ação da alma;

2. Pela qual é chamada inteligente; 
3. E a forma para qual se dirige é uma certa coisa imaginária e fictícia;

4. Que o espírito elabora para si quando e como quer.

No ponto 1 Abelardo já determina que a intelecção é mais uma afecção da alma partindo do pressuposto aristotélico, de que a alma é dotada de faculdades. Confirma isso ao dizer que: "[...] tanto os sentidos quanto o intelecto são próprios da alma" (ABELARDO, 2010, p. 234). Ou seja, esta "certa ação da alma", chamada de intelecto é mais uma faculdade cognitiva.Intelligere (2) é o nome desta faculdade que "apreende os significados" na alma. Assim como no entendimento denominado por Aristóteles, Abelardo faz da inteligência peça central da cognição. A "coisa imaginária e fictícia" (3) a qual se refere, nada mais é do que a ligação entre a intelecção e a imaginação. São faculdades diferentes, no entanto, o intelecto usa a imaginação para produzir imagens na mente, que serão significadas pelo intelecto. Temos então, a imaginação produzindo a imagem, para que o intelecto possa, fazendo uso da razão, gerar significados. O ponto 4 deve ser ressaltado, pois demarca uma característica da imaginação que não pode ser esquecida: "quando e como quer". A imaginação - partindo de uma lembrança de percepções do sensível elabora imagens quando se faz necessário. Diferente do olho que, ao ver, imediatamente gera uma percepção, a imaginação seria uma lembrança do que este olho viu. Podendo ser confusa e criando elaborações que não existem na realidade, a exemplo de seres mitológicos. É, portanto, uma elaboração que o espírito entende que não é o objeto em si, nem algo puramente racional.

Neste sentido, a percepção do objeto e a intelecção poderiam ser confundidas como um só movimento da alma, desta forma, faria com que o intelecto fosse semelhante não a imagem do objeto, mas ao objeto em si. Contudo, não é assim. Ao inteligir ao mesmo tempo em que se percebe pelos sentidos a alma tem a "verdadeira substância da coisa". Isso acontece, pois as imagens geradas pela imaginação são passíveis de erro. Ao se deparar com o objeto em si, o intelecto não precisa do uso das imagens geradas por imaginação. Já a percepção pelos sentidos está diretamente ligada ao objeto particular.

Sobre os tipos de intelecção Abelardo diz que existe a abstração - que se manifesta de dois modos - e a conjunção. A abstração trata-se da ação de direcionar a atenção só à matéria ou só à forma. Ou ainda, ora para matéria, 
ora para forma. Ou seja, sem modificar em nada do objeto em questão, é possível abstrair apenas uma determinada parte ou abstrair as partes separadamente. No caso da conjunção, o espírito entende a matéria e a forma misturadas. Apesar dos dois tipos de intelecção, o magister irá tratar, sobretudo, da abstração.

O processo abstrativo gera na mente uma imagem confusa, pois quando abstraímos apenas a forma ou matéria, estamos lidando com algo que não existe no mundo, a saber, nem um objeto é composto somente de forma ou somente de matéria. As sensações fazem o papel de perceber o objeto como um todo através dos sentidos, no entanto, as sensações não fornecem o entendimento de todas as coisas. Ou seja, pelo uso dos sentidos não temos acesso ao entendimento do universal. O conhecimento do universal se dá pelo processo intelectivo. E intelecção tratada no Logica Ingredientibus é fruto da abstração.

Podemos dar vários exemplos do processo abstrativo:

1. Uma estátua composta de ouro e bronze $-\mathrm{Na}$ qual a atenção é direcionada ora ao ouro, ora ao bronze.

2. A palavra universal "Homem"-Sendo possível abstrair ora a noção de animal, ora de mortal, ora de bípede, etc.

3. Seres imaginários, como um minotauro - Abstraindo a sua parte semelhante a um homem e a cabeça que se assemelha a de um touro. Nos três exemplos, o que vemos em comum é que o intelecto, por meio da abstração, é capaz de direcionar sua atenção apenas a uma parte do objeto. A estátua não passa a ser somente de bronze no momento em que ele é abstraído, e sim, tão somente a parte que corresponde ao bronze é observada. Portanto, para ele: "[...] o modo de entender é diferente do modo de subsistir" (ABELARDO apud ESTEVÃO, 2010, p. 241). Do mesmo modo, da palavra homem, no momento em que é abstraído o conceito de animal, não perde a noção de bípede ou mortal. Sobre o imaginário, fictício ou mitológico, falaremos mais tarde.

Ainda sobre o processo abstrativo, Abelardo se questiona a respeito das abstrações vazias. Pois é possível pensar que, se as abstrações se dirigem para algo que não existem em separado, na realidade, elas seriam vazias e falsas. Porém, não é assim. Sabemos que as sensações podem levar a erro e da mesma 
forma, às imagens confusas fruto da intelecção. $\mathrm{O}$ homem não é detentor de um conhecimento puro e perfeito, o único que tem esta capacidade é Deus. Abelardo esclarece isso no Tractatusao abordar os tipos de intelecções, a que elas se referem e suas limitações como elementos constituintes do conhecimento.

Sobre o fictício - como as criaturas mitológicas - Abelardo dirá que não são intelecções, e sim, o uso da imaginação. No exemplo de um ser mitológico, ele não existe no real, portanto não pode ser percebido pelas sensações, nem tampouco, podemos as inteligir, mas não há formas individuais a serem abstraídas. Trata-se da imaginação criando uma imagem com partes que nós já conhecemos. Assim como podemos recordar o passado e prever um futuro, através da imaginação podemos ter imagens de seres e objetos que não existem. E desta forma, se faz possível pensar um minotauro, quimera e os demais seres fictícios.

É através das intelecções que temos acesso ao tipo de conhecimento que não for possível pelos sentidos.

$\mathrm{Na}$ verdade, toda a intelecção como ela é, e "se" é difícil conseguir uma intelecção de qualquer coisa que não está sujeito à sensação, que não concebem em "outra" coisa que não existe? Ou por abstração que chamamos essas intelecções que quer representar mentalmente uma forma em si mesma - sem considerar o assunto - ou meditar em qualquer tipo indiferente, ou seja: sem distinguir os "indivíduos" que se materializam (ABELARDO, Des Intellections, 1994, p. 70)

Estes tipos de intelecções ainda podem ser classificados como verdadeiros ou falsos. Essa definição -verdadeira e falsa - é feita através da relação da proposição inteligida com a realidade. Isto é analisado de duas formas, a saber, pelo status e o dictumpropositionis.("quase coisa", que representa a relação das palavras na proposição. Ele é o que a proposição expressa, ou ainda, o que é "dito pela proposição"). A intelecção verdadeira é dada dentro da proposição. É nesse sentido que Abelardo tira a discussão do campo ontológico e passa para o linguístico.

Muito embora, opinião e imaginação sejam conceitos diferentes, estão interligados a partir do Tractatus de Intellectibus, pois a criação de uma imagem mental, através da imaginação, pode levar a crença de que aquela "forma tal" existe. Sabemos, no entanto, que se trata de uma opinião baseada nos sentidos. Enquanto naLogica Ingredientibus não há conhecimento sem imaginação, no 
Tractatus de Intellectibus, a opinião está abaixo da intelecção, pois a segunda estaria completamente fundamentada na racionalidade e, portanto, uma vez tida como sã e verdadeira, não estaria passível a erros. Enquanto a opinião, baseada na crença de algo, poderia facilmente levar a uma falsa intelecção.

\section{Conclusão}

A intelecção é a imagem que as coisas geram na mente, mas não são as coisasmesmas. E esta intelecção é obtida por meio da abstração que a mente faz dos universais.A abstração se trata de discernir o "estado da coisa" a ser inteligido. É ela que nos dá àcapacidade de pensar as coisas que não são separadas separadamente; varia de acordocom a "intenção" da mente.

Para concluir digo que o uso da racionalidade (Diferencia-se aqui intelecção e racionalidade, pois a intelecção está ligada à razão, porém não são a mesma coisa. A intelecção é uma ação da alma.) serve para proporcionar à mente o entendimento do mundo: sendo a formação desseentendimento/pensamento como linguagem mental e das palavras - voz significativa. Desta forma, entender como ocorre oprocesso intelectivo, em Pedro Abelardo, também é entender o processo de formação do conhecimento.

\section{Referências}

ABELARDO, Pedro. (1994) Lógica para principiantes. Introd. e trad. de C. A. R. do Nascimento. Petrópolis: Vozes. . (1994) Des Intellections. Ed., trad.et notes par Patrick Morin. Paris: Vrin. . (1979) Lógica para principiantes. São Paulo: Abril Cultural.

DE BONI, Luis Alberto (org.). (1995) Lógica e linguagem na Idade Média. Porto Alegre: EDIPUCRS.

DIAS, Cleber Santos. (2007) O processo cognitivo no Tractatus de Intellectibus e na Dialética de Pedro Abelardo. Porto Alegre. (Tese).

KNEALE, W.; KNEALE, M. (1991) O desenvolvimento da lógica. 3. ed. Trad. de M. S. Lourenço. Lisboa: Fundação Calouste Gulbenkian.

LEITE, Júnior. (2001) O problema dos universais: a perspectiva de Boécio, Abelardo e Ockahm. Porto Alegre: Edipucrs. 
Perspectiva Filosófica, vol. 44, n. 2, 2017

MARENBON, J. (1997) The philosophy of Peter Abelard. Cambridge: UP.

NASCIMENTO, C. A. R. do. (1983) A querela dos universais revisitada. Cadernos PUC - Filosofia. São Paulo, EDUSC.

PINBORG, Jan. (1984) Logica e semantica nel medievo. Torino: Editora Boringhieri.

PORFÍRIO. (2002) Isagoge: introdução às Categorias de Aristóteles. Trad. introd. e comentários de Bento Silva Santos. São Paulo: Attar Editorial. 